\title{
MEIO AMBIENTE URBANO NA JURISPRUDENCIA INTERNACIONAL EUROPEIA
}

\author{
Marcelo Dias Varella \\ Doutor em Direito pela Université Paris 1 Pantheon-Sorbonne, PARIS 1, França. \\ Mestre em Direito pela Universidade Federal de Santa Catarina (UFSC). \\ Professor do Centro Universitário de Brasília (UniCEUB). \\ E-mail: marcelodvarella@gmail.com
}

Mariane Morato Stival

Doutoranda em Direito no Centro Universitário de Brasília (UniCEUB)

Mestre em Direito e Políticas Públicas (UniCEUB) Professora e Pesquisadora do Curso de Direito do Centro

Universitário de Anápolis (UniEVANGÉLICA)

E-mail: marianemoratostival@hotmail.com

\section{RESUMO}

Este artigo objetiva analisar o reconhecimento do direito ao meio ambiente urbano pela jurisprudência internacional europeia. A Corte Europeia de Direitos Humanos (CEDH) adotou o sofisticado método da interpretação evolutiva dinâmica e criou parâmetros para a construção do direito à qualidade de vida ambiental em suas decisões que envolvem problemas urbanos, desde a década de 90 . O artigo busca apresentar a inovadora ampliação do alcance normativo da jurisprudência internacional europeia sobre a criação do direito à qualidade de vida ambiental urbana. Para o desenvolvimento do artigo em relação à metodologia, será apresentada a bibliografia, a legislação e a jurisprudência internacional específica sobre o assunto. Serão analisados os argumentos jurídicos desenvolvidos nas decisões ambientais da Corte Europeia, identificando-se as principais questões jurídicas levantadas e como são interpretados os casos sobre meio ambiente urbano. Diante da ampla e efetiva jurisprudência ambiental urbana europeia, entende-se que são possíveis interações normativas entre os sistemas regionais de proteção aos direitos humanos com vistas 
a contribuições da jurisprudência da CEDH para a criação de uma nova tipologia de jurisprudência ambiental urbana em outras cortes internacionais e nacionais.

Palavras-chave: Proteção ambiental urbana; Qualidade de vida; Direitos Humanos; Interpretação evolutiva.

\title{
URBAN ENVIRONMENT IN EUROPEAN INTERNATIONAL JURISPRUDENCE
}

\begin{abstract}
This paperaims to analyze the recognition of the right to the urban environment by european international jurisprudence. The European Court of Human Rights (ECHR) adopted the sophisticated method of dynamic evolutionary interpretation and created parameters for the construction of the right to environmental quality of life in its decisions involving urban problems, since the 1990s. The paper seeks to present the innovative extension of scope normative of the European international jurisprudence on the creation of the right to the urban environmental quality of life. For the development of the paper, about the methodology, will be presented the bibliography, the legislation and the specific international jurisprudence about the subject. The legal arguments developed in the environmental decisions of the European Court will be analyzed, identifying the main legal issues raised and how the cases about the urban environment are interpreted. In view of the wide and effective European urban environmental jurisprudence, it is understood that possible normative interactions between regional systems for the protection of human rights by contributing to ECHR jurisprudence for the creation of a new typology of urban environmental jurisprudence in other international and national Courts.
\end{abstract}

Keywords: Urban environmental protection; Quality of life; Human rights; Evolutionary interpretation. 


\section{INTRODUÇÃO}

A Corte Europeia de Direitos Humanos (CEDH) inovou ao criar o direito à qualidade de vida ambiental urbana, reconhecendo-o como norma de direito humano em sucessivos casos. ${ }^{1}$ Mesmo sem um dispositivo ambiental expresso na Convenção Europeia de Direitos Humanos, a Corte desenvolveu o método da interpretação dinâmica e evolutiva da proteção ambiental, o qual insere o reconhecimento do meio ambiente urbano como direito humano nos casos em que a questão ambiental afeta os direitos fundamentais expressos nessa Convenção, como o direito à saúde, à vida privada e familiar, à propriedade privada e a outros direitos materiais e processuais.

A proteção ambiental relaciona-se com a proibição de ingerências no direito à vida privada e familiar, previsto no art. $8^{\circ}$ da Convenção Europeia de Direitos Humanos. Não existe um direito autônomo ao meio ambiente. Um dos pontos mais inovadores é a criação do direito à qualidade de vida do indivíduo diante de violações ambientais, o qual é reconhecido a partir de um ativismo judicial da $\mathrm{CEDH}$, em uma atividade de interpretação do art. $8^{\circ}$ da Convenção sobre o direito à vida privada e familiar.

O presente artigo apresentará as inovações da CEDH em relação à proteção do meio ambiente urbano, com a construção de um novo direito à qualidade de vida ambiental em sua jurisprudência. No aspecto metodológico, a escolha do direito à qualidade de vida ambiental urbana não ocorreu de forma aleatória, mas sim de forma consciente acerca de seu aspecto inovador, caracterizado na postura de buscar a construção de um artigo sobre um direito que não existe na Convenção Europeia, mas é construído pela Corte Europeia de Direitos Humanos por meio de uma interpretação evolutiva das decisões ambientais, a qual tem contribuído para a consolidação e efetividade das decisões ambientais nos países europeus.

Será feita a análise dos casos da CEDH a partir dos temas que se apresentam como direitos violados. A CEDH tem uma ampla e diversificada jurisprudência ambiental urbana, que vem sendo construída desde a década de 90. Não foram consideradas todas as decisões da CEDH sobre meio ambiente urbano. A escolha pautou-se na identificação das decisões que

1 A Corte confirmou este entendimento no julgamento do caso López Ostra vs. Espanha, entendendo que atividades poluidoras estavam causando danos ao meio ambiente, à saúde e à qualidade de vida da vítima e de seus familiares. Devem-se observar as normas urbanísticas com o objetivo de garantir um desenvolvimento urbano com boa qualidade de vida para as pessoas. 
foram utilizadas sucessivamente pela Corte, até os casos em que houve o efetivo reconhecimento do direito à qualidade de vida ambiental, diante de problemas urbanos.

Inicialmente, será apresentada a forma de criação e de reconhecimento do direito ao meio ambiente urbano na jurisprudência internacional europeia; e, posteriormente, no segundo tópico do artigo, será feita a análise dos sucessivos casos ambientais urbanos julgados pela CEDH como: Bistrovic vs. Croácia, Budayeva vs. Rússia, Fredin vs. Suécia, Nima Kapsali vs. Grécia, Hamer vs. Bélgica, Depalle vs. França, Arrondelle vs. Reino Unido, Powell e Rayner vs. Reino Unido, López Ostra vs. Espanha, Guerra e outros vs. Itália, Moreno Gómez vs. Espanha, Fadeyeva vs. Rússia, Grimkovskaya vs. Ucrânia, Ledyayeva e outros vs. Rússia e Oneryildiz vs. Turquia. Serão apresentados os principais aspectos jurídicos das decisões desses casos, que contribuíram para a criação do direito à qualidade de vida ambiental urbana.

\section{CONCEITO DE QUALIDADE DE VIDA AMBIENTAL URBANA NA JURISPRUDENCIA INTERNACIONAL EUROPEIA}

A jurisprudência da CEDH, a partir de uma interpretação evolutiva dinâmica, reconhece o direito à qualidade de vida ambiental em casos de violação dos direitos à vida privada e familiar, à saúde, à propriedade, assim como de violação de direitos processuais em problemas ambientais urbanos, como os direitos à informação, ao acesso à Justiça, ao recurso efetivo, ao julgamento justo e às garantias judiciais, condenando os Estados que integram o sistema europeu por denegação de qualidade de vida ambiental.

Os sistemas regionais de proteção aos direitos humanos são inspirados nos valores e princípios da Declaração Universal de 1948 e integram o universo de proteção dos direitos humanos no plano internacional. Diante dessa complexidade de instrumentos internacionais, cabe ao indivíduo que sofreu a violação de seu direito a escolha do aparato mais favorável, tendo em vista que, eventualmente, direitos idênticos são tutelados por dois ou mais instrumentos de alcance global ou regional. Nesta ótica, os diversos sistemas de proteção de direitos humanos podem interagir em benefício dos indivíduos protegidos (DELMAS-MARTY, 2003). 
A Corte Europeia demonstra, de forma expressa, seu respeito por questões ecológicas em diversos contextos, concedendo atenção especial aos casos de atividades que causam danos ao meio ambiente. Essa relevância alçada pelo sistema europeu ressalta a preocupação com outros valores da sociedade e sintetiza um reflexo de que a $\mathrm{CEDH}$ não tem ignorado o fato de que a sociedade, de uma forma geral, tem intensificado sua preocupação na preservação do meio ambiente e do direito à boa qualidade de vida (VARELLA, 2013).

Com o surgimento de ações internacionais relacionadas a problemas ambientais urbanos, a CEDH desenvolveu um sofisticado método de interpretação evolutiva, em que, mediante a conexão do direito à vida privada e familiar, à saúde e à proibição de tratamentos desumanos e degradantes, criou um direito à qualidade de vida ambiental a partir de problemas urbanos, em uma visível atividade de criação judicial do direito. A jurisprudência ambiental do sistema europeu abrange uma diversidade de temas ambientais urbanos, que variam desde graves problemas de poluição até casos que envolvem altos ruídos de aeroportos (MAROCHINI, 2014).

A CEDH considera as particularidades locais e que os Estados apresentam melhores condições de solucionar determinados litígios relacionados a problemas ambientais urbanos. Considerando o caráter dinâmico das questões urbanísticas, as normas ambientais podem sofrer entraves para sua legitimação no contexto urbano. Trata-se de um critério que vem sendo utilizado pela CEDH, para garantir uma maior aceitação e efetividade das decisões ambientais e a implementação de políticas pelos Estados condenados (LEWIS, 2002, p.03).

No âmbito da proteção ambiental, a Corte evoluiu no sentido de ter que construir novos conceitos para abranger e fundamentar casos de violação do meio ambiente, especialmente no contexto urbano. Durante este estudo da jurisprudência internacional da CEDH, é possível observar a interpretação evolutiva dinâmica, em que a Corte, por meio de uma conexão com outros direitos, criou um direito à qualidade de vida ambiental. A partir da decisão de um caso ambiental, a Corte, ao longo do tempo, construiu outras decisões ambientais mais sofisticadas nos casos subsequentes, citando as decisões anteriores como referência nos argumentos. A criação do direito ocorre de forma evolutiva.

Um dos pontos em comum dos casos julgados pela CEDH e relacionados a questões ambientais é que os danos atingem a saúde e a qualidade de vida das vítimas. Trata-se de problemas com características 
que se originam das próprias atividades ambientais lesivas. Assim, na maioria dos casos, uma cláusula geral ambiental em relação à proteção dos direitos das pessoas, no contexto europeu, está implícita no art. $8^{\circ}$ da Convenção Europeia de Direitos Humanos, que trata do direito à vida privada e familiar com qualidade (KAYSER, ${ }^{1991)}$.

Há uma conexão entre o direito à vida privada e familiar, à saúde e à proibição de tratamentos desumanos e degradantes, os quais são interpretados pela CEDH de uma forma evolutiva e dinâmica para a criação do direito específico à qualidade de vida ambiental, em seus diversos contextos, abrangendo o meio ambiente urbano. Houve a criação da jurisprudência que inseriu esse direito no contexto europeu, reconhecendoo como norma internacional de direito humano.

$\mathrm{Na}$ proteção desse direito, juntamente com direito à saúde e à qualidade de vida, surge o conceito de qualidade de vida ambiental. Certamente, é de grande complexidade obter uma definição precisa desse direito, considerando sua subjetividade e a intensa atividade de interpretação da CEDH em sua construção. Na decisão do caso López Ostra vs. Espanha, é possível observar a posição da Corte sobre o alcance normativo desse direito.

Neste caso, a Corte Europeia admitiu a violação do art. $3^{\circ}$ da Convenção, considerando as graves consequências na interferência do meio ambiente urbano, com a intensidade do cheiro, do barulho e da emissão de gases nocivos e poluidores que estavam causando danos à saúde da requerente e de sua família, pois havia sido instalada uma usina de resíduos sólidos nas proximidades de sua residência.

A Corte decidiu que a qualidade de vida ambiental é uma característica subjetiva de imprecisa conceituação. O reconhecimento de um direito subjetivo, com características difusas concedeu a esse tribunal uma margem de discricionariedade interessante, que pode eximir a requerente de demonstrar completamente as lesões à sua saúde. Trata-se de uma grande novidade: a proteção ambiental da saúde, do bem-estar e da qualidade de vida. O direito à saúde e ao bem-estar seriam macroconceitos, e um nível de qualidade de vida ambiental é suscetível de tutela jurídica diante de violações de direitos fundamentais. (CEDH, 1994).

É importante destacar que a jurisprudência ambiental da Corte Europeia criou o direito subjetivo ao meio ambiente, mesmo com algumas dificuldades de natureza interpretativa. Com as amplas possibilidades de conexão do direito ao meio ambiente com outros direitos humanos, é 
possível verificar a existência uma proteção substantiva e uma proteção que envolve direitos procedimentais. A inovação da CEDH em relação ao meio ambiente é a criação do direito à qualidade de vida ambiental, o qual é resultado de uma atividade de interpretação de direitos materiais como a saúde, a propriedade privada, o direito à vida privada e familiar, o direito à informação e ao processo equitativo, todos previstos de forma expressa na Convenção Europeia.

\section{INOVAÇÃO DA JURISPRUDÊNCIA DA CEDH SOBRE MEIO AMBIENTE URBANO}

Sobre a incidência do art. $8^{\circ}$ da Convenção Europeia de Direitos Humanos no direito ao meio ambiente urbano, observa-se que a importância desse direito se deve à convergência da doutrina das obrigações positivas com a interpretação dinâmica do conceito de vida privada e familiar. Essa interpretação evolutiva abrange outros bens jurídicos, compreendendo o direito à saúde e à qualidade de vida. Logo, níveis mínimos desses direitos são suscetíveis de tutela jurídica, mesmo que individual, por interferências de terceiros, conforme a jurispudência da CEDH (JARVIS, 1999).

Uma importante evolução da jurisprudência ambiental urbana da Corte ocorreu na decisão Powell e Rayner vs. Reino Unido. Este foi o primeiro caso em que a CEDH se pronunciou sobre meio ambiente e qualidade de vida, em 21 de fevereiro de 1990. O caso se refere aos altos ruídos (poluição sonora) produzidos pelo Aeroporto de Heathrow, em Londres, que causaram danos aos requerentes. É importante mencionar que a CEDH examinou este caso na perspectiva do art. $8^{\circ}$ da Convenção. A CEDH reconheceu que o desenvolvimento urbano pode, em determinadas situações, apresentar-se como violação do direito à boa qualidade de vida das pessoas (BAQUER, 2005).

Em sua decisão, a CEDH destacou que

\footnotetext{
Deve haver uma obrigação positiva do poder público em proteger a vida privada dos demandantes. Logo, mesmo com as medidas tomadas pelas autoridades visando diminuir os efeitos dos ruídos, assim como a importância do aeroporto de Heathrow e a complexidade das decisões normativas sobre a matéria, a CEDH concluiu que o Estado não havia utilizado todos os seus meios de atuação e que este caso violava o artigo $8^{\circ}$ da Convenção Europeia. A Corte encerrou sua decisão concluindo que
} 
as vítimas estavam sofrendo danos com os altos níveis de distúrbios sonoros do aeroporto (CEDH, 1990, § 45).

Nos casos submetidos à CEDH e relacionados ao direito ao meio ambiente urbano, observa-se que as principais questões jurídicas dos casos se apresentam de três maneiras diferentes. Em primeiro lugar, direitos humanos protegidos pela Convenção Europeia podem ser diretamente afetados por fatores ambientais, como cheiros tóxicos de uma fábrica ou disposição irregular do lixo, causando um impacto negativo sobre a vida e a saúde dos indivíduos (PAVONI, 2015).

Em um segundo contexto, fatores como a instalação de empreendimentos que causam impactos no meio ambiente podem dar origem a certos direitos processuais para o indivíduo, como o direito de informação, de participação nos processos e de acesso à Justiça, envolvendo casos ambientais. Por fim, a proteção do meio ambiente apresenta-se como um objetivo legítimo, que justificaria a interferência em certos direitos humanos como a restrição do direito de propriedade (PAVONI, ${ }^{2015)}$.

Nos casos a serem apresentados a seguir, é possível identificar que os problemas de natureza ambiental, no âmbito da $\mathrm{CEDH}$, afetam o direito de propriedade, previsto no art. $1^{\circ}$ do Protocolo 1 à Convenção Europeia, o direito à vida, previsto no art. $2^{\circ}$, o direito à vida privada $\mathrm{e}$ familiar, previsto no art. $8^{\circ}$, o direito a um julgamento justo e o acesso à justiça previstos no art. $6^{\circ}$, todos da Convenção Europeia de Direitos Humanos.

\subsection{O direito à propriedade privada como direito ao meio ambiente urbano}

Nos casos de violações do direito à boa qualidade de vida e ao meio ambiente sadio, um tema levantado como questão jurídica nos casos é o direito à propriedade privada, o qual está previsto no art. $1^{\circ}$ do Protocolo 1 à Convenção Europeia. Trata-se do direito de desfrutar da propriedade de forma pacífica, sendo possível incluir uma carga ecológica a esse direito.

$\mathrm{O}$ direito à propriedade privada não garante, de forma ampla, o direito de desfrutar da propriedade em um meio ambiente sadio. A Corte Europeia já decidiu que não basta uma simples perturbação das condições de desfrutar desse direito, sendo preciso constatar uma diminuição do valor econômico da propriedade privada. Trata-se de uma interpretação restrita 
desse direito. Pela análise da jurisprudência se observa, na realidade, uma consequência lógica de natureza econômica do direito de propriedade formada por um conjunto de situações jurídicas de natureza patrimonial (SHERLOCK, 2000).

No âmbito da jurisprudência da $\mathrm{CEDH}$, é escassa a conexão do direito de propriedade com assuntos relacionados ao meio ambiente, ao contrário do sistema interamericano de direitos humanos. Em relação ao direito de propriedade, a CEDH relaciona o dano ambiental com a comprovação de diminuição do valor econômico do bem. Um caso interessante sobre meio ambiente e direito de propriedade é o caso Bistrovic vs. Croácia.

Neste caso, os requerentes possuíam uma casa e um terreno em Gojanec, na Croácia. A empresa pública Croata Roads requereu a expropriação de uma parte do terreno dos requerentes para a construção de uma estrada. Os requerentes opuseram-se a esta proposta, solicitando que sua propriedade fosse expropriada em sua totalidade. Os requerentes alegaram que a desapropriação parcial deixaria o imóvel sem utilidade, uma vez que a casa e as terras agrícolas representavam uma unidade inseparável. Alegaram que, na qualidade de agricultores, os requerentes não podiam utilizar sua propriedade sem acesso aos tratores e aos outros veículos utilizados na atividade agrícola, e a expropriação parcial impediria esse acesso (CEDH, 2007).

Além disso, segundo constava no projeto, a estrada passaria a, aproximadamente, $25 \mathrm{~m}$ (vinte e cinco metros) da propriedade e causaria uma considerável poluição sonora, devido à elevada frequência de tráfego. Os requerentes salientaram que a construção de paredes de proteção contra o ruído prejudicaria o aspecto visual de sua casa, sem protegê-los, de forma eficaz, do ruído e da poluição (CEDH, 2007).

Outro problema referia-se à desvalorização do bem, pois, com a expropriação parcial, o valor da propriedade remanescente diminuiria consideravelmente, uma vez que a construção da estrada privaria os requerentes da boa condição de vida que gozavam, como o acesso direto à estrada, um ambiente agradável, um enorme pátio e uma baixa exposição ao ruído.

A CEDH seguiu sua linha de interpretação sobre o direito de propriedade em questões ambientais, reconhecendo que o caso se referia a uma perda efetiva de cunho econômico, e o poder público deveria adotar medidas de proteção. A CEDH decidiu que, diante de um caso de 
expropriação pelo Estado que trará um impacto negativo ao meio ambiente, deve haver uma valoração do referido impacto sobre o valor dos bens, para que se possa fixar uma justa indenização (CEDH, 2007).

A questão torna-se mais complexa quando a CEDH vincula a responsabilidade do poder público a uma obrigação de proteção. É possível verificar essa relação na comparação dos casos Oneryldiz vs. Turquia e Budayeva vs. Rússia. No primeiro caso, que se refere a graves danos causados em razão de uma explosão de gás metano no depósito de lixo de Umraniye, a CEDH reconheceu a violação do direito de propriedade, tendo em vista que as consequências foram comprovadas pelas graves negligências imputáveis ao Estado e pela perda de vidas, em razão do soterramento da residência do requerente (DOTHAN, 2011).

A Corte, neste caso, decidiu que a lesão não se deu em razão da ingerência do Estado, mas sim do descumprimento de uma obrigação positiva, pois as autoridades não fizeram todo o possível para proteger os interesses de cunho patrimonial das vítimas. Logo, afirmou que a obrigação positiva prevista no art. $1^{\circ}$ do Protocolo 1 da Convenção Europeia de Direitos Humanos determina que as autoridades devem adotar medidas de precauções efetivas para impedir a destruição da propriedade dos requerentes (CEDH, 2004).

No caso Budayeva vs. Rússia, o qual se refere a um deslizamento de lodo de rios, também considerado trágico, a CEDH reconheceu a violação de direito de propriedade, mesmo que a origem do fato não se encontrasse em uma atividade humana. Reiterando a decisão do caso Oneryldiz vs. Turquia, a CEDH considerou que o efetivo exercício do direito de propriedade não dependia unicamente de uma obrigação do Estado de não interferir, mas também da adoção de medidas positivas de proteção (CEDH, 2008).

A CEDH argumentou que, em ações advindas de atividades humanas, a obrigação de proteção da propriedade é análoga à proteção do direito à vida, mas deve haver uma maior flexibilidade nos casos de desastres naturais. No caso em análise, mesmo tratando-se de desastre natural, houve uma compensação indenizatória. Ocorre que a CEDH, partindo de seu entendimento de que deve haver uma flexibilização em casos de desastres naturais, decidiu que a obrigação positiva do Estado em proteger a propriedade privada não pode ser interpretada no sentido de obrigar o Estado a indenizar totalmente o valor de mercado das propriedades destruídas. Verifica-se que a CEDH realizou um juízo de equidade sobre a questão da indenização. 
Para a $\mathrm{CEDH}$, as restrições por parte das autoridades públicas sobre o direito do indivíduo em sua propriedade devem ter um objetivo legítimo, que pode ser a proteção do meio ambiente. As medidas tomadas em busca de um objetivo legítimo devem estar em conformidade com a lei, que deve ser acessível e ter seus efeitos previsíveis. As medidas tomadas devem ser proporcionais ao objetivo pretendido, ou seja, um justo equilíbrio deve ser atingido entre os interesses individuais e coletivos (DOTHAN, 2011).

Nesse aspecto, a CEDH já reconheceu que a justiça local de cada país está em uma posição melhor do que a Corte para julgar como equilibrar os diferentes níveis de interesses em cada caso. A CEDH concede ao Estado uma margem nacional de apreciação, objetivando garantir uma maior liberdade aos Estados na decisão de casos que envolvem políticas de planejamento local e de conservação do meio ambiente. Assim, sua interferência na proteção do direito de propriedade limita-se aos casos em que a ingerência nos direitos individuais seja desproporcional (SPIELMAN, 2012).

Na decisão do caso Fredin vs. Suécia, a CEDH considerou que a restrição ao uso da propriedade foi justificada em benefício do direito coletivo ao meio ambiente. Este caso se refere à revogação de uma licença para operar um poço de cascalho situado em um terreno do requerente, com base na Lei de Conservação da Natureza. A CEDH considerou que a revogação da licença causou ao requerente considerável perda, mas não houve violação do direito de propriedade. A decisão apresentou uma base jurídica que garantia o interesse coletivo na proteção do meio ambiente (CEDH, 1991).

ACorte argumentou que o requerente estava ciente da possibilidade que as autoridades tinham de revogar sua licença. A decisão destacou que a revogação da licença do requerente de usar sua propriedade não era desproporcional ao objetivo legítimo dessa revogação - qual seja, a proteção do meio ambiente -, concluindo que não houve violação do direito de propriedade previsto no art. $1^{\circ}$ do Protocolo 1 da Convenção Europeia.

$\mathrm{Na}$ decisão do caso Nima Kapsali vs. Grécia, a CEDH considerou que, em questões relacionadas a planejamento urbano e meio ambiente, a avaliação das autoridades nacionais deve prevalecer, a menos que não sejam razoáveis. Neste caso, foi revogada pelas autoridades administrativas locais uma licença de construção em uma área ambiental. Foi feita pelo poder público uma sequência de análises aprofundadas de todos os aspectos dos problemas ambientais, em razão das atividades de construção; e ficou 
demonstrado que não houve indicação alguma de que a decisão de revogação da licença havia sido arbitrária ou ilegal. A Corte Europeia considerou que a revogação da licença de exploração da área não era desproporcional em relação ao objetivo de proteção do meio ambiente e, como resultado, concluiu que o pedido deveria ser julgado improcedente (CEDH, 2004).

$\mathrm{O}$ caso Hamer vs. Bélgica refere-se à demolição de uma casa de férias construída em 1967 pelos pais do requerente, sem a devida licença de construção. Em 1994, o poder público elaborou dois relatórios: um, relativo ao corte de árvores na propriedade como forma de violação das normas florestais; e o outro, sobre a construção da casa em uma área florestal, sem licença. O requerente alegou violação do direito de propriedade; entretanto, a $\mathrm{CEDH}$ decidiu que as autoridades tinham interferido no direito do requerente a respeito de sua propriedade, mas que houve uma justificativa legítima, qual seja, a proteção do meio ambiente na área em questão (CEDH, 2007).

Quanto à proporcionalidade da medida impugnada, a Corte ponderou que o meio ambiente é um bem cuja proteção deve ser uma questão de preocupação constante para a coletividade. Imperativos econômicos e até mesmo alguns direitos fundamentais, como o direito de propriedade, não devem ter prioridade sobre a proteção do ambiente, especialmente se o Estado havia observado a legislação sobre o assunto. Como resultado, a Corte decidiu que as restrições ao direito de propriedade podem ser permitidas, desde que um justo equilíbrio seja considerado entre os interesses individuais e coletivos (DOTHAN, 2011).

No mesmo sentido foi o julgamento do caso Depalle vs. França. Este caso se refere a uma ordem para os requerentes demolirem suas casas, que haviam sido construídas à beira-mar, em uma área de propriedade pública marítima onde não havia direitos formais de propriedade ou direito de ocupação temporária (CEDH, 2010).

Os proprietários possuíam apenas decisões judiciais antigas, que os autorizavam a ocupar esta área na costa, mas não conferiam qualquer direito de propriedade. As autoridades locais condenaram os demandantes a restaurar o local de acordo com seu estado original, demolindo as construções sobre a propriedade pública e sem direito a nenhuma indenização. A decisão foi tomada no contexto da implementação de políticas públicas de proteção do meio ambiente.

O papel da CEDH no julgamento desse caso era de garantir que um justo equilíbrio fosse alcançado entre as exigências do interesse geral da 
comunidade (proteção ambiental e acesso gratuito à costa) e as do interesse dos demandantes, que pretendiam manter seu direito de propriedade. A CEDH reconheceu que o Estado teve um amplo poder de apreciação em suas decisões em relação ao planejamento regional e às políticas de conservação ambiental em que o interesse geral da comunidade foi prioritário.

A CEDH considerou que os requerentes sempre tiveram ciência de que as autorizações de ocupação da propriedade eram precárias e revogáveis. Assim, a Corte decidiu que não houve violação do direito de propriedade previsto no art. $1^{\circ}$ do Protocolo 1 da Convenção Europeia.

Pela análise da jurisprudência da $\mathrm{CEDH}$ sobre o direito de propriedade, pode-se constatar que, nos termos do art. $1^{\circ}$ do Protocolo $\mathrm{n}$. 1 da mencionada Convenção, os indivíduos têm direito ao gozo pacífico dos seus bens, incluindo-se a proteção contra a privação ilegal de sua propriedade. Esse dispositivo também reconhece que as autoridades públicas têm o direito de controlar o uso da propriedade de acordo com o interesse da coletividade. É possível identificar que as decisões da CEDH se têm consolidado sob o argumento de que o meio ambiente é uma consideração cada vez mais importante e prioritária.

Observa-se que o interesse coletivo na proteção do meio ambiente urbano pode justificar determinadas restrições por parte das autoridades públicas sobre o direito individual ao uso pacífico da propriedade. Essas restrições devem ser legais e proporcionais ao objetivo legítimo almejado. As autoridades públicas desfrutam de uma ampla margem de apreciação para decidir sobre a escolha dos meios mais adequados e para verificar se as consequências da execução são justificadas pelo interesse coletivo. As medidas praticadas pelo poder público devem ser proporcionais, devendo haver um justo equilíbrio entre os interesses envolvidos (DOTHAN, 2011).

A proteção do direito à propriedade privada pode exigir das autoridades públicas o cumprimento de normas ambientais. O exercício efetivo desse direito não depende apenas do dever das autoridades públicas de não interferir, mas pode obrigar o Estado a tomar medidas positivas para proteger esse direito. A CEDH, nos julgamentos dos casos, constatou que essa obrigação positiva pode surgir em relação a atividades perigosas e, em menor proporção, em situações de desastres naturais. 


\subsection{A proteção da vida privada e familiar como direito ao meio ambiente urbano}

O direito à vida é expressamente regulamentado pela Convenção Europeia de Direitos Humanos, em seu art. $2^{\circ}$. Trata-se de um direito que não obriga apenas o poder público de abster-se de causar a morte de forma voluntária, mas também de adotar obrigações positivas no sentido de garantir medidas necessárias e efetivas para a proteção da vida das pessoas em seu território. Estabelecendo uma conexão entre o direito à vida e o direito ao meio ambiente, a Corte reconhece que essa obrigação estatal abrange o contexto de toda atividade pública que cause riscos ao direito à vida, incluindo-se as de natureza industrial e as que são perigosas por natureza.

Para Kant, o valor da vida tem como elemento fundamental a dignidade da pessoa, pois os seres racionais apenas são chamados de pessoas porque sua natureza os distingue como fins em si mesmos, ou seja, como algo que não pode ser utilizado apenas como meio. Todo ser humano é detentor de dignidade. Trata-se de um valor que não tolera equivalências. A vida e a dignidade de uma pessoa são inegociáveis (KANT, 2008).

$\mathrm{Na}$ conexão entre o direito ao meio ambiente e o direito à boa qualidade de vida, a previsão com maior alcance normativo da Convenção Europeia de Direitos Humanos é o direito ao respeito à vida privada e familiar, previsto em seu art. $8^{\circ}$. A CEDH declara, em sua jurisprudência ambiental, que esse dispositivo prevê uma abrangente proteção contra emissões nocivas. Trata-se de um artigo que permite uma ampla interpretação, considerando que é utilizado pela CEDH para fundamentar decisões sobre proteção familiar, eutanásia e casos de violação do direito à privacidade.

Para a Corte, o art. $8^{\circ}$ abrange o meio ambiente a partir da confluência da doutrina de obrigações positivas, com uma interpretação dinâmica do conceito de vida privada e familiar. Essa interpretação evolutiva resulta na subsunção ao abrigo dessa disposição de dois bens jurídicos não compreendidos de forma expressa no artigo: saúde e qualidade de vida. (YARZA, 2012)

$\mathrm{O}$ art. $8^{\circ}$ da $\mathrm{CEDH}$, por meio do princípio da interpretação evolutiva, permite que esse direito se apresente como um verdadeiro catalisador da proteção ambiental na jurisprudência internacional europeia. A relação entre a proteção ambiental e 0 art. $8^{\circ}$ da Convenção não é 
recente, sendo possível encontrar algumas decisões da extinta Comissão Europeia, no início dos anos 80. Entretanto, a relação do art. $8^{\circ}$ com a proteção ambiental era incipiente e, na década de 90 houve uma evolução da jurisprudência da Corte, que constrói suas decisões com um amplo alcance normativo nos casos sobre meio ambiente urbano.

A relação entre danos ambientais e a proteção da vida teve início no julgamento do caso Arrondelle vs. Reino Unido, em outubro de 1980. Neste caso, a moradia da requerente se tornou inabitável em razão da poluição sonora do Aeroporto de Gatwick, em Londres. Diante da ausência de ações efetivas por parte das autoridades públicas, a extinta Comissão reconheceu a violação do direito à vida privada. Neste caso houve uma solução amistosa, e o caso não foi submetido a julgamento pela Corte Europeia (CEDH, 1980).

O primeiro caso em que a CEDH se pronunciou sobre a qualidade de vida ambiental, em fevereiro de 1990, foi na decisão de Powell e Rayner vs. Reino Unido. Este caso, que também se refere a problemas relacionados à poluição sonora no Aeroporto de Heathrow. Neste caso, havia uma Lei de Aviação Civil, de 1982, que excluía, em seu art. 76, a responsabilidade dos empresários de aeronaves em caso de ruídos. Logo, os requerentes não dispunham de um recurso no direito interno que permitisse requerer uma indenização pelos danos causados. A importância deste caso está no fato de que a Corte Europeia reconheceu a relação entre o bem jurídico - previsto no art. $8^{\circ}$ da Convenção Europeia - e o direito à qualidade de vida dos requerentes, por problemas ambientais urbanos (CEDH, 1990).

A CEDH reconheceu que existia uma obrigação positiva do poder público em proteger a vida privada dos requerentes. Mesmo com as providências adotadas pelo governo para diminuir os efeitos dos ruídos, e não obstante a importância do Aeroporto de Heathrow e a complexidade das decisões normativas sobre a matéria, a CEDH concluiu que o Estado não havia utilizado todos os seus meios de solução do problema e que este caso violava o art. $8^{\circ}$ da Convenção Europeia.

Um caso importante em que se observa a interpretação evolutiva da CEDH foi no julgamento de López Ostra vs. Espanha. A relação entre o direito à vida privada e o meio ambiente urbano deixou de ser hipotético, $\mathrm{e}$ os argumentos da decisão foram construídos de forma fundamentada pela Corte, em uma constatação de uma efetiva violação do art. $8^{\circ}$ da Convenção. Para a construção da decisão deste caso, a Corte utilizou o precedente do caso Powell e Rayner vs. Reino Unido. 
O caso refere-se a um dano ambiental ocorrido na cidade de Lorca, onde uma usina de tratamento de resíduos sólidos que funcionava sem licença do poder público causou o vazamento de poluentes, afetando a saúde da população da região. Houve omissão do poder público no caso e, assim, a requerente recorreu à Corte Europeia, argumentando que a emissão de poluentes na região estava violando seu direito à boa qualidade de vida, assim como seu direito de não ser submetida a tratamentos desumanos e degradantes (CEDH, 1994).

Neste caso, a CEDH considerou que, embora o poder público não fosse o responsável direto pelo dano causado, permitiu a construção de uma fábrica em uma área imprópria, assim como subsidiou a construção das instalações. A Corte Europeia decidiu que, mesmo que as leis e regulamentos internos tivessem sido cumpridos pelo Estado, o que deve ser determinado é se o Estado tomou todas as medidas necessárias para garantir o direito da vítima à sua sadia vida familiar.

O caso López Ostra foi fundamentado no art. $8^{\circ}$ da Convenção Europeia, que prevê o direito à vida privada e familiar, e no art. $3^{\circ}$ da mesma Convenção, que garante o direito da requerente de não ser submetida a tratamento cruel e degradante, considerando que a intensidade do cheiro, do barulho e da emissão de gases poluidores causaram danos à saúde da vítima (CEDH, 1994).

A CEDH analisou a relação entre o meio ambiente urbano, a qualidade de vida e o art. $8^{\circ}$ da Convenção com muita clareza, destacando os princípios aplicáveis às obrigações positivas do poder público na proteção ambiental e na garantia do direito à qualidade de vida e de saúde da requerente. Concluiu que as autoridades públicas não atuaram com a devida diligência e, assim, o direito previsto no art. $8^{\circ}$ havia sido violado.

A sentença do caso López Ostra foi utilizada no julgamento do caso Guerra vs. Itália. Neste caso, os requerentes residiam nas proximidades de uma fábrica de fertilizantes. Houve uma explosão da torre de purificação de gases de amoníaco, contaminando o ar com carbonato de potássio e trióxido de arsênio, levando cerca de cento e cinquenta pessoas aos hospitais, com estado de saúde grave (CEDH, 1998).

Os requerentes alegaram a falta de medidas efetivas para a redução dos níveis de poluição e a existência de riscos de acidentes graves decorrentes das atividades da fábrica. Neste caso, as questões jurídicas relevantes se referem à violação do direito ao respeito à vida privada $\mathrm{e}$ familiar e do direito à liberdade de informação, pois não foram informados 
previamente à população, os riscos das atividades e eventuais procedimentos em caso de acidente grave.

A CEDH, na decisão deste caso, considerou que houve uma violação do art. $8^{\circ}$ da Convenção e que o Estado Italiano não havia cumprido sua obrigação de garantir o direito das vítimas de respeito à vida privada e familiar. A Corte decidiu que a grave poluição ambiental pode afetar o bem-estar dos indivíduos e impedi-los de desfrutar de suas moradias, de tal modo que afete sua vida privada e familiar (CEDH, 1994).

Outro caso em que a CEDH confirmou o precedente López Ostra foi o denominado Moreno Gómez vs. Espanha. O caso envolve dano ambiental com poluição sonora. $\mathrm{O}$ requerente vivia em um apartamento em um bairro residencial de Valência desde 1970. A Câmara Municipal estava permitindo a abertura de discotecas nas proximidades da casa do requerente, o que tornava o local inabitável em razão do barulho. Diante dos problemas causados pelo ruído, a Câmara Municipal encomendou um relatório de um perito, que verificou que os níveis de ruído estavam em desacordo com a legislação ambiental e urbanística (CEDH, 2004). A Câmara Municipal proibiu o funcionamento de novas atividades no local.

Mesmo com as proibições estabelecidas, a Câmara emitiu uma autorização de funcionamento de uma nova discoteca no prédio em que o requerente residia. Ele apresentou uma reclamação no Conselho Municipal de Valência, sem a obtenção de respostas. Ajuizou um pedido de revisão judicial no Superior Tribunal de Justiça da Espanha, que foi indeferido em julho de 1998 (CEDH, 2004).

O requerente interpôs recurso perante o Tribunal Constitucional da Espanha, o qual decidiu que a vítima não havia provado a existência de uma efetiva relação entre o ruído e o dano, de forma que violasse direitos previstos na legislação constitucional. O requerente alegou que as autoridades da Espanha foram responsáveis pelos danos e que o ruído resultante poluição sonora representava uma violação de seu direito a uma boa qualidade de vida, previsto no Art. $8^{\circ}$ da Convenção Europeia de Direitos Humanos (CEDH, 2004).

$\mathrm{ACEDH}$ observou que o requerente vivia em uma área com graves problemas ambientais relacionados a poluição sonora. A Corte considerou que houve violação dos direitos protegidos pelo art. $8^{\circ}$ da Convenção Europeia. Embora a Câmara Municipal tivesse adotado medidas para a solução do problema, a concessão de mais licenças contribuiu para o desrespeito contínuo das regras que o próprio órgão havia estabelecido. 
A CEDH considerou que o requerente havia sofrido uma grave violação do direito à sadia qualidade de vida, em razão da omissão das autoridades em adotar providências para eliminar as perturbações noturnas; e considerou que o governo da Espanha não conseguiu cumprir sua obrigação de garantir o direito ao respeito da vida privada do requerente, violando o art. $8^{\circ}$ da Convenção Europeia (CEDH, 2004).

$\mathrm{Na}$ jurisprudência ambiental analisada, a Corte reconheceu que a poluição ambiental urbana pode afetar a saúde e a qualidade de vida das pessoas. De acordo com a Corte, o direito ao respeito à moradia refere-se ao uso tranquilo da residência, dentro de limites razoáveis. As violações desse direito não estão limitadas a interferências como a entrada ilegal no domicílio de uma pessoa, mas também podem resultar de problemas ambientais como altos níveis de ruídos, emissões de poluentes ou outras formas similares de violação do meio ambiente urbano.

Seguindo a interpretação evolutiva, a Corte, na decisão do caso Grimkovskaya vs. Ucrânia, reafirmou que, para caracterizar o art. $8^{\circ}$ da Convenção, o perigo deve atingir um alto nível de gravidade, resultando em um real impedimento para o requerente desfrutar de sua casa; e que há a necessidade de uma avaliação de todas as circunstâncias do caso para que seja aferido o nível de gravidade. Neste caso, foi construída uma rodovia em uma rua que havia sido projetada, inicialmente, como residencial (CEDH, 2011).

Para a construção da rodovia, não houve sistema de pavimentação ou de revestimento adequado capazes de suportar altos volumes de tráfego de veículos pesados. $\mathrm{O}$ requerente alegou que sua casa havia se tornado inabitável, e as pessoas que viviam na região estavam sofrendo com as constantes vibrações provocadas pelo tráfego, pelos altos ruídos e com a poluição.

A Corte considerou que não havia provas suficientes sobre todas as alegações do requerente, como o impacto do problema sobre a saúde dos moradores da região; e baseou-se em provas que comprovaram que o nível de poluição sonora e atmosférica foi acima dos limites legais. Concluiu que os altos níveis de ruídos e a poluição do ar gerada pela estrada violaram os direitos do requerente, previstos no art. $8^{\circ}$ da Convenção (CEDH, 2011).

Nos casos Ledyayeva vs. Rússia e Fadeyeva vs. Rússia, a Corte Europeia constatou que a instalação e o funcionamento de uma usina siderúrgica que emitia poluentes em uma área urbana causou danos à população das cidades, pois as pessoas estavam em uma área de alto risco 
para a súde e estavam submetidas às emissões de poluentes tóxicos da usina (CEDH 2006). A Corte decidiu que o governo não havia adotado providências para a proteção dos direitos das vítimas.

Houve violação do direito à sadia qualidade de vida, diante da grave poluição ambiental. $\mathrm{O}$ poder público não realizou a remoção das famílias para um local seguro e não foi garantida uma reparação para as pessoas que deixaram suas casas em busca de um lugar fora da área de risco. No julgamento desses casos, a Corte destacou a falta de capacidade do Estado em regular as atividades ambientais desenvolvidas por empresas privadas.

A interpretação evolutiva da jurisprudência internacional europeia abrange outros bens jurídicos, que compreendem o direito à saúde e a qualidade de vida. Esses direitos são suscetíveis de proteção em casos de danos ambientais, conforme jurispudência da CEDH. A Corte desenvolveu uma inovadora ampliação do alcance normativo de outros direitos humanos, por meio da interpretação de bens jurídicos protegidos em casos de danos ao meio ambiente urbano (PRING, 2016).

Observa-se que a Corte Europeia interpreta o direito ao meio ambiente por uma via reflexa, e a jurisprudência é desenvolvida colocando a questão ambiental conectada com a proteção dos direitos humanos. A Corte decide, constantemente, que questões ambientais urbanas demandam um sério comprometimento do setor público e privado no desenvolvimento de ações voltadas ao interesse da coletividade. Um controle rigoroso deve ser feito entre o interesse coletivo e o dano sofrido pelo indivíduo, a partir do ponto de vista dos seus direitos fundamentais.

\section{CONSIDERAÇÕES FINAIS}

A Corte Europeia de Direitos Humanos apresenta uma considerável evolução de sua jurisprudência sobre meio ambiente urbano, a qual relaciona os casos ambientais com o direito à sadia qualidade de vida das pessoas. Esse direito foi criado pela Corte a partir da interpretação do direito à vida privada e familiar com o direito à saúde, o direito de propriedade e com os demais direitos materiais e processuais previstos na Convenção Europeia. Não existe previsão específica da proteção ambiental na legislação, mas há o reconhecimento do direito à qualidade de vida ambiental urbana pela CEDH. 
A partir da conjugação do art. $8^{\circ}$ da $\mathrm{CEDH}$ com os direitos fundamentais previstos na Convenção Europeia, a $\mathrm{CEDH}$ reconhece o direito ao meio ambiente urbano sadio, utilizando o método de interpretação evolutiva dinâmica. Conclui-se que essa criação é resultado das interpretações de uma sequência de casos ambientais que foram submetidos à Corte, cujas decisões foram se sofisticando a partir de cada julgamento, o que justifica a característica "evolutiva dinâmica". Em termos processuais, a CEDH protege o direito de intervenções das pessoas no processo de tomada de decisões, como um valor fundamental para o direito ao meio ambiente com qualidade.

A jurisprudência da $\mathrm{CEDH}$, mesmo com a possibilidade de demandas coletivas, temumacaracterística maisindividualista, considerando os efeitos das violações sobre um indivíduo ou uma família, com um foco maior em questões levantadas acerca de poluição atmosférica e sonora, dentre outros problemas ambientais urbanos. Os direitos processuais vêm sendo utilizados de forma consistente no exercício do direito ambiental, como o acesso à informação, participação, consulta e acesso à justiça.

Conclui-se que a Corte tem produzido parâmetros internacionais que podem contribuir para o avanço da jurisprudência de outros tribunais internacionais e nacionais, na forma de conectar o direito ao meio ambiente à boa qualidade de vida urbana. Mesmo com as características peculiares do direito internacional ao meio ambiente, o qual dispõe de frágeis mecanismos de cogência, executoriedade e coercibilidade, os Estados não apresentam resistência em ratificar tratados desta natureza, ou seja, há um bom nível de aceitação em ser parte de uma norma internacional sobre questões ambientais.

É nesse contexto que se entende que, por meio de diálogos normativos e uma interpretação evolutiva e dinâmica do direito ao meio ambiente urbano, seja possível uma ampliação do alcance da jurisprudência de outros sistemas regionais, a exemplo da Corte Interamericana de Direitos Humanos, a qual apresenta falhas no reconhecimento do direito ao meio ambiente urbano. Conclui-se, ainda, que a inovadora criação jurisprudencial da CEDH do direito à qualidade de vida ambiental pode influenciar, além da jurisprudência interamericana, a própria jurisprudência brasileira. A ideia é o diálogo entre cortes para abranger possíveis temas ambientais urbanos.

Considerando as amplas e inovadoras formas de interpretar casos ambientais, as decisões da CEDH podem alterar o atual alcance normativo 
dos sistemas de proteção aos direitos humanos nos casos de violações ambientais no contexto urbano. Destaca-se que o objetivo não seria resolver os problemas ambientais das cidades, mas contribuir para a ampliação do alcance da jurisprudência sobre o direito à qualidade de vida ambiental urbana. Uma maior interação entre os tribunais internacionais e nacionais é fundamental para o futuro dos próprios sistemas. O diálogo entre cortes é uma interação complexa, mas implica a importância de formas inovadoras na produção de jurisprudência sobre o meio ambiente urbano.

\section{REFERÊNCIAS}

BAQUER, Lorenzo Martín-Retortillo. Lo médio ambiente y la calidad de vida junto a la necesidad de dar cumplimiento a las Sentencias. Revista española de derecho administrativo. N. 125, 2005.

CEDH. Arrondelle vs. Reino Unido, decisão de 15 de julho de 1980.

CEDH. Budayevas vs. Rússia, decisão de 20 de março de 2008.

CEDH. Bistrovic vs. Croácia, decisão de 31 de maio de 2007.

CEDH. Depalle vs. França, decisão de 29 de março de 2010.

CEDH. Fadeyeva vs. Russia, decisão de 9 de junho de 2005.

CEDH. Fredin vs. Suécia, decisão de 18 fevereiro de 1991.

CEDH. Grimkovskaya vs. Ukraine, decisão de 21 de julho de 2011.

CEDH. Guerra e outros vs. Itália, decisão de 19 de fevereiro de 1998.

CEDH. Hamer vs. Bélgica, decisão de 27 de novembro de 2007.

CEDH. Ledyaeva vs. Russia, decisão de 26 de outubro de 2006.

CEDH. López Ostra vs. Espanha, decisão de 09 de dezembro de 1994.

CEDH. Moreno Gomez vs. Espanha, decisão de 16 de novembro de 2004.

CEDH. Nima-Kapsali vs. Grécia, decisão de 23 de setembro de 2004.

CEDH. Oneryldiz vs. Turquia, decisão de 30 de novembro de 2004. 
CEDH. Powell e Rayner vs. Reino Unido, decisão de 21 de fevereiro de 1990.

DELMAS-MARTY, Mireille. Étude juridiques comparatives et internationalisation du droit. Paris: Collège de France/Fayard, 2003.

DJEFFAL, Christian. Dinamic and Evolutive Interpretation of the ECHR by Domestic Courts. Series: International Law in Domestic Legal Orders, Oxford University Press, 2016.

DOTHAN, Shai. Judicial Tactics in the European Court of Human Rights. Public Law \& Legal Theory Working Papers, v. 12, 2011.

JARVIS, Françoise. The European Convention on Human Rights and The Environment, European Law Review, 1999.

KANT, Immanuel. A metafisica dos costumes. 2. ed. Trad. Edson Bini. Bauru, SP: Edipro, 2008.

KAYSER, Pierre. La protection de la vie privée, 2e éd. Revue internationale de droit compare, v. 43, 1991.

LEWIS, Bridget. Environmental Rights or A Right to the environment? Exploring the nexus between human rights and environmental protection. 2012. Disponível em: http://papers.ssrn.com/sol3/DisplayAbstractSearch. cfm. Acesso em: 12 abr. 2017.

MAROCHINI, Maša. The interpretation of the European Convention on human rights. Collected Papers of the Faculty of Law in Split. 2014, v. 51, p. 63-84. Disponível em: http://hrcak.srce.hr/file/171985. Acesso em: 25 mar. 2017.

PAVONI, Ricardo. Environmental Jurisprudence of the European and InterAmerican Courts of Human Rights: Comparative Insights. In: B. Boer (ed.), The Environmental Dimension of Human Rights. Oxford, 2015.

PRING, George. Environmental Courts and Tribunals, United Nations Environment Programme, 2016. Disponível em: http://wedocs.unep.org/ bitstream/handle/20.500.11822 /10001/environmental-courts-tribunals. pdf?sequence=1. Acesso em: 18 mar. 2017.

SHERLOCK, Ann. The European Convention on Human Rights, European 
Law Review, 2000.

SONELLI, Silvia. The Dialogue between National Courts and the European Court of Human Rights: Comparative Perspectives. University of Leicester School of Law Research, Paper no. 14, 2014. Disponível em: SSRN: https:// ssrn.com/abstract=2421034. Acesso em: 3 mar. 2017.

SPIELMAN, Dean. Allowing the Right Margin the European Court of Human Rights and the National Margin of Appreciation Doctrine: Waiver or Subsidiarity of European Review? CELS Working Paper Series, University of Cambridge, 2012.

TRINDADE, A.A. C. Direitos Humanos e Meio Ambiente: Paralelo dos sistemas de proteção internacional. Porto Alegre: Sergio Antonio Fabris, 1993.

VARELLA, Marcelo Dias. Internacionalização do Direito: Direito Internacional, Globalização e Complexidade, UniCEUB, 2013.

YARZA, Fernando Simón, Medio ambiente y derechos fundamentales. Tribunal Constitucional y Centro de Estudios Politicos y Constitucionales, Madrid, 2012.

Artigo recebido em: 01/06/2017. Artigo aceito em: 01/08/2017.

\section{Como citar este artigo (ABNT):}

VARELLA, Marcelo Dias; STIVAL, Mariane Morato. Meio ambiente urbano na jurisprudência internacional europeia. Veredas do Direito, Belo Horizonte, v. 14, n. 29, p. 373-395, mai./ago. 2017. Disponível em: < http:// www.domhelder.edu.br/revista/index.php/veredas/article/view/1077>. Acesso em: dia mês. ano. 